\title{
Expressions of masculinity and associations with suicidal ideation among young males
}

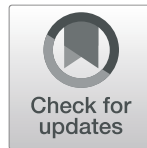

Tania L. King ${ }^{1 *}$ D, Marissa Shields', Victor Sojo ${ }^{2}$, Galina Daraganova ${ }^{3}$, Dianne Currier ${ }^{4}$, Adrienne O'Neil $^{5}$, Kylie King ${ }^{6}$ and Allison Milner ${ }^{1 \wedge}$

\begin{abstract}
Background: Adolescent boys and young men are at particular risk of suicide. Suicidal ideation is an important risk factor for suicide, but is poorly understood among adolescent males. Some masculine behaviors have been associated with deleterious effects on health, yet there has been little quantitative examination of associations between masculinity and suicide or suicidal ideation, particularly among boys/young men. This study aimed to examine associations between conformity to masculine norms and suicidal ideation in a sample of adolescents.

Methods: A prospective cohort design, this study drew on a sample of 829 Australian boys/young men from the Australian Longitudinal Study on Male Health. Boys were 15-18 years at baseline, and 17-20 years at follow-up. Masculine norms (Wave 1), were measured using the Conformity to Masculine Norms Inventory (CMNI-22). Suicidal ideation (Wave 2) was a single-item from the Youth Risk Behavior Survey. Logistic regression analysis was conducted, adjusting for available confounders including parental education, Indigenous Australian identity and area disadvantage.
\end{abstract}

Results: In adjusted models, greater conformity to violent norms ( $O R=1.23,95 \%$ Confidence Interval [CI]: 1.03-1.47) and self-reliance norms $(O R=1.40,95 \% \mathrm{Cl}: 1.15-1.70)$ was associated with higher odds of reporting suicidal ideation. Greater conformity to norms regarding heterosexuality was associated with reduced odds of reporting suicidal ideation ( $O R=0.80,95 \% \mathrm{Cl}: 0.68-0.91)$.

Conclusions: These results suggest that conforming to some masculine norms may be deleterious to the mental health of young males, placing them at greater risk of suicidal ideation. The results highlight the importance of presenting young males with alternative and multiple ways of being a male. Facilitating a relaxation of norms regarding self-reliance, and encouraging help-seeking, is vital. Furthermore, dismantling norms that rigidly enforce masculine norms, particularly in relation to heteronormativity, is likely to benefit the broad population of males, not only those who do not conform to heterosexual and other masculine norms.

Keywords: Masculinity, Suicidal ideation, Young males

\section{Background}

Mental health problems increase during the period of adolescence [47], and for young people aged 10-24 years, mental disorders are the largest contributor to the global burden of disease [25]. Many risk factors and health problems faced by adolescents as they transition through this period are gender specific [3], and on some

\footnotetext{
* Correspondence: tking@unimelb.edu.au

We dedicate this paper to the memory of Allison Milner, who was tragically killed after this paper was written.

${ }^{1}$ Centre for Health Equity, Melbourne School of Population and Global Health, The University of Melbourne, Bouverie St, Carlton 3010, Australia Full list of author information is available at the end of the article
}

indicators of mental health, such as suicide, adolescent boys and young men are at particular risk [1]. Despite this, adolescent male health has long been neglected. However there is now growing recognition of the extent to which this population is underserved, particularly in relation to unmet mental health care needs [54].

Globally, suicide is the third most common cause of death for adolescent males [65] and in Australia, suicide is the leading cause of death for males aged 15-24 years [1]. It is often during adolescence that the onset of suicidal and self-harming behaviors occurs [29], and rates of self-injury (a known risk factor for suicide [52];) are

(c) The Author(s). 2020 Open Access This article is distributed under the terms of the Creative Commons Attribution 4.0 International License (http://creativecommons.org/licenses/by/4.0/), which permits unrestricted use, distribution, and reproduction in any medium, provided you give appropriate credit to the original author(s) and the source, provide a link to the Creative Commons license, and indicate if changes were made. The Creative Commons Public Domain Dedication waiver (http://creativecommons.org/publicdomain/zero/1.0/) applies to the data made available in this article, unless otherwise stated. 
typically higher among adolescents than among adults [45]. Research examining risks related to adolescent suicide have typically focused on family factors and psychiatric disorders, but it is recognized that other underresearched factors may also be important and should be investigated [29]. Masculinity, and its associated practices and behaviors is one potential avenue of investigation.

\section{Conceiving masculinity}

Conceptualizations of masculinity have shifted away from the notion of a singular 'masculinity', toward recognition of a multiplicity of 'masculinities' [14, 32]. Among these multiple masculinities, there exists an idealized or 'hegemonic' masculinity that represents the currently accepted ideal $[14,32]$. The norms of masculinity are contestable (shifting across time, space and context), as well as relational (hierarchically positioned and performed in relation to femininity and nonhegemonic masculinities [14]). Consistent with this, there is evidence that conformity to masculine norms varies by age [53], and that conformity to masculinity is most strongly endorsed by younger males [53].

The social norms that define appropriate masculine roles and behaviors are assimilated from a young age [7]. The pressure to conform to masculine ideals can be immense [2], and there are often social penalties for boys and men who deviate from normative masculine roles and behaviors [57]. Confinement to the set of behaviors considered to appropriately affirm masculinity can also severely delimit healthy behaviors and emotional responses [2] that might otherwise buffer young males during the often stressful period of adolescence.

\section{Masculinity among adolescent males}

Australia is a diverse country, with many cultural and historical influences shaping its masculine identities. For Australian adolescent males, the physical practice of masculinity is principally located in two key domains: sexuality and sport [15]. For many adolescent Australian boys, sport provides an arena for 'ritualized combat' ([15] pg 15), camaraderie and strength. Heterosexuality is central to normative Australian masculinity, and sport has traditionally been a key setting for the display of hetero-masculinity [15]. This is similar for young males elsewhere: a recent systematic review of studies from 29 (mostly Western) countries examining gender attitudes indicated that physical strength, toughness and competitiveness, and heterosexual prowess were central to adolescent masculine norms [34]. Recent evidence indicates that young Australian men are becoming more progressive on some elements of masculinity, with lower endorsement of norms regarding violence, more openness to partaking in traditionally female activities such as household tasks and cooking, and greater openness to having gay friends being recently observed [59]. Some masculine norms however, remain entrenched: many young men retain ideals of 'acting strong', being the primary breadwinner and 'fighting back when pushed around' [59].

\section{The gender paradox in suicide}

While suicide is a leading cause of death among adolescent males in Australia [1] and worldwide [65], there is little understanding of why. Researchers have also observed evidence of a 'gender paradox' in suicide, with males more likely to die by suicide, while females have higher rates of non-fatal suicidal behaviors [9, 38]. Evidence among 14-15 year old Australian adolescents also reflects these international patterns, with more girls than boys reporting suicidal behaviors (including ideation, making a plan and attempting suicide) [20], and more young males dying by suicide [1].

\section{Ideation-to-action framework}

Suicidal ideation is recognized as a putative and proximal risk factor for suicide attempts [37], and contemporary models of suicide recognize this relationship [37, $58,62]$. The process by which suicidal thoughts progress to action is poorly understood, and this lack of understanding is posited to underpin the limited success in reducing suicides worldwide [37]. It is recognized that many commonly cited risk factors for suicide such as depression, hopelessness and impulsivity, also predict suicidal ideation, and do not necessarily differentiate those who have attempted suicide, from those who have reported ideation, but have not attempted [37]. The ideation-to-action framework proposes that the development of ideation, and the progression from ideation to attempts be conceived as distinct processes with separate predictors and explanations [37]. Acquired capability for suicide is considered to be a key factor that may explain the progression from ideation to attempts [33,37].

There is some evidence that males may be at greater risk of death by suicide because they are socialized to conform to certain masculine norms that foster engagement with painful and provocative life events, resulting in greater 'acquired capability' for suicide [26]. It is known that certain physical practices more common among men and boys, such as physical violence and risky behaviors, such as drinking, smoking and dangerous driving, are associated with increased health risks $[15,18]$. Given these factors, the effect of masculine norms and socialization on health and health behaviors has become an increasing focus of investigation [12, 13, 49]. It is argued that high conformity to masculine ideals of toughness and emotional neutrality may have harmful 
effects on the mental health of males [18]. This has prompted calls to apply a masculinities perspective to suicidal behavior [13].

\section{Masculinity as a risk factor for suicidal ideation}

There is an emerging body of work examining masculinity and gender roles as a risk factor for suicidal ideation and suicide in young adults and adolescents $[13,50]$. In a large sample of US college students, there was evidence that what the authors termed 'traditional' masculinity was associated with suicidal ideation [13]. Psychological autopsies of young men aged 18-30 who had died by suicide in Norway indicated that identifying with unattainable masculine ideals was a key risk factor in these suicides, and death by suicide was theorized to represent an act of masculinity that compensated for this perceived failure to attain idealized masculine standards [50]. Relatedly, among a group of young men aged 18-30 years who had attempted suicide, it was found that conformity to masculine norms about emotional containment prevented young men from disclosing the extent of their distress [12]. Among young men of a similar age (18-24 years), being in a peer group that valued self-reliance and repudiated help-seeking, inhibited help-seeking by young men at risk of suicide, and drove them to adopt risky coping behaviors, such as alcohol use [39]. Consistent findings emerged from a recent meta-analyses, with evidence that certain masculine norms are related to poorer mental health-related outcomes [64].

Not all masculine norms are associated with adverse effects however [64], and it is likely that some dimensions of masculinity are positively associated with mental health and wellbeing. Further, while endorsement of certain masculine norms such as self-reliance is associated with suicidal ideation [49] and poorer mental health in adults [43], less is known about adolescent males.

\section{Study aims}

Suicidal ideation is an understudied phenomena, particularly in relation to masculinity [13] and to our knowledge, no quantitative study has prospectively examined associations between masculinity and suicidal ideation in an Australian population-based sample of adolescent males. The aim of the study was exploratory, and sought to examine associations between conformity to different masculine norms and suicidal ideation among Australian adolescent males. Better understanding of potentially damaging (and health promoting) masculine norms among adolescents is critical if we are to identify ways to promote the mental health and wellbeing of male adolescents and young men.

\section{Methods}

\section{Study design and setting}

We used data from Waves 1 and 2 of the Australian Longitudinal Study on Male Health (Ten to Men) [6]. Ten to Men is a longitudinal cohort study of Australian boys and men aged $10-55$ years at baseline, and collects data on five broad domains (physical health, mental health and wellbeing, health behaviors, social determinants of health, and health service use and knowledge).

Details of the sampling, recruitment, and data collection methods of the Ten to Men study have been published elsewhere [19]. The study commenced in 2013/ 2014 with a cohort of 15,988 males aged $10-55$ years. Wave 2 of data collection was conducted between November 2015 and May 2016 with 76\% of the original cohort participating. Surveys were self-completed. The current analysis drew on the Ten to Men sample of adolescents who were 15-18 years at baseline (Wave 1), and 17-20 years at follow-up.

\section{Measures \\ Exposure variable: conformity to masculine norms}

The Conformity to Masculine Norms Inventory (CMNI22) was used to assess masculinity and was collected at Wave 1. The CMNI was designed to measure the extent to which males conform to masculine norms. The CMNI-22 is an abbreviated version of the original 94item scale, using the two highest loading statements to assess conformity to each masculine norm subscale [46]. Pairs of statements correspond to 11 subscales: (1) Primacy of Work; (2) Dominance; (3) Risk-Taking; (4) Heterosexual presentation; (5) Power over Women; (6) Emotional Control; (7) Playboy; (8) Violence; (9) Pursuit of Status; (10) Winning; and (11) Self-Reliance.

It should be noted that in some research, the fourth subscale is referred to as 'disdain for homosexuals'. Following the precedent of other work [49], we refer to this factor as heterosexual presentation, noting that the two items used to derive this factor reflect the importance of being perceived to be heterosexual, and a fear of being perceived to be gay, rather than homophobia.

The CMNI instructs respondents to consider their actions, feelings, and beliefs when rating their agreement or disagreement with each statement. Response options range from "strongly disagree" (0) to "strongly agree" (3). Responses to each item were summed to provide a conformity score for each subscale ranging from 0 to 6 [41]. Scores from each of the 11 subscales were summed to present a continuous, global score of conformity to masculine norms from 0 to 66 (higher scores indicating greater conformity to masculine norms). Studies typically report associations using the total CMNI score, however there is evidence that different subscales can be associated with different outcomes, and reliance on the 
overall score can obfuscate such associations [24]. We therefore examined the different subscales, as well as the overall score. These were analyzed as continuous variables.

\section{Outcome variable: suicidal ideation}

The primary outcome variable used in this analysis was a single-item from the Youth Risk Behavior Survey, and asked: Have you seriously thought about killing yourself in the past 12 months? [10]. Responses were coded as a binary variable (yes/no) and collected at Wave 2 only, approximately 2 years after Wave 1 data collection.

\section{Covariates}

Previous work has shown associations between adolescent suicide/suicidal behaviors and area disadvantage [28], race/ethnicity [38] and Indigenous Australian identity [21]. It is also known that masculinity varies by race/ ethnicity [27], and area disadvantage [12]. Given these associations, we included the following covariates as confounders in analytical models: country of birth (Australia, born elsewhere); Indigenous Australian identity (Aboriginal and/or Torres Strait Islander, nonAboriginal or Torres Strait Islander); area disadvantage. The area disadvantage variable was derived using the Australian Bureau of Statistics' [4] Index of Relative Socio-Economic Disadvantage (IRSD). IRSD values were categorized into quintiles (based on the sample distribution), with the lowest quintile (Quintile 1) reflecting areas of greatest disadvantage.

\section{Participants}

We restricted the sample to adolescents aged 15-18 years at baseline. As with most cohort studies, there was some loss to follow-up between the two waves: of the 1333 young men aged 15-18 at Wave 1, 960 participated in Wave 2 of data collection. Our eligible sample was defined as those participating in both waves of data collection $(n=960)$. Of these, 935 provided outcome data. There was a small amount of missing data $(<4 \%)$ for all exposures, outcomes and covariates, and $7.9 \%$ missing for the total CMNI score, reducing our analytic sample to $n=829$ (see Additional file 1: Table S1).

Comparing the analytic sample with the eligible sample, there was no difference in terms of the masculinity subscales, suicidal ideation, or country of birth. The eligible sample however, contained a slightly higher proportion of Indigenous Australians $(4.2 \%$ of eligible sample, compared to $3.0 \%$ of analytic sample) and a slightly lower proportion were living in an area of least disadvantage $(21.8 \%$ in eligible sample compared to $24.4 \%$ in analytic sample).

As for most longitudinal studies, most of the missing data in this analysis was due to participant drop out.
While multiple imputation is one of the methods available to address missing data, imputing dependent (outcome) variables does little to improve model efficiency [66]. On this basis, and as most of our missing data was due to missing outcomes, we chose not to use multiple imputation to handle the missing data. Figure 1 illustrates the flow of participants from baseline, through to the eligible and analytic samples.

\section{Analytical approach}

To our knowledge, no previous study has examined the scale properties of the CMNI with Australian adolescents. Given this, we firstly assessed the internal reliability of the CMNI and then conducted confirmatory factor analysis. Descriptive analyses of exposures, confounders, and outcomes were conducted, followed by logistic regression in which models were adjusted for potential confounders (area disadvantage, Indigenous Australian identity, country of birth). As we were interested in the effect of each masculinity subscale, independent of the other subscales, separate regression models were conducted for each masculinity subscale.

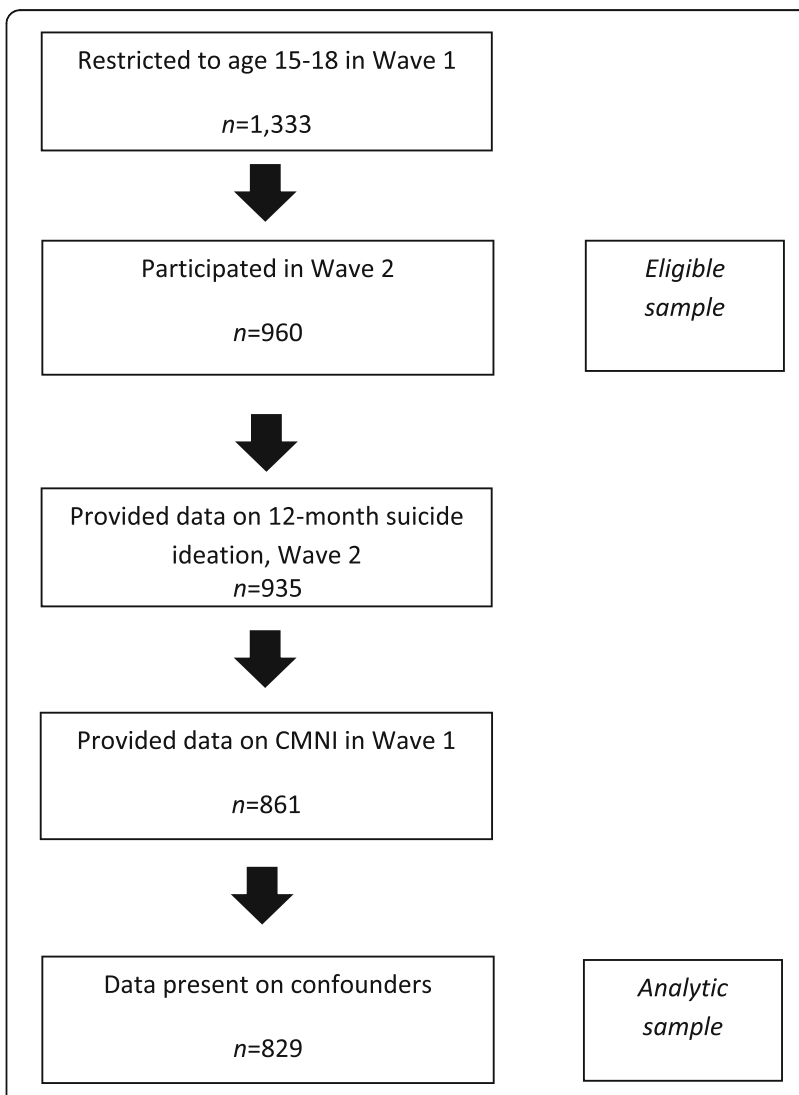

Fig. 1 Participants in sample 


\section{Sensitivity analysis}

As it is possible that conformity to masculine norms varies by sexual orientation, we conducted sensitivity analysis in which we adjusted for sexual orientation (heterosexual; gay/ bisexual/other/unsure; see Additional file 1: Table S2 and S3). In further analyses, we also restricted analysis to the sample of young men identifying as heterosexual (See Additional file 1: Table S4).

\section{Results}

We conducted confirmatory factor analysis to assess the factor structure of the CMNI among the adolescent sample. We employed an oblique rotation, as this accommodates the assumed correlated nature of the factors. Following Kaiser criteria, we retained eigenvalues of 1 or higher. In the derived 11-factor structure, item loadings confirmed the factor structure of the CMNI (see Additional file 2: Tables S5 and S6). Internal consistency of the overall CMNI among the adolescent sample was assessed using Guttman's $\lambda-4$, and was calculated to be 0.86 .

Table 1 shows the characteristics of the final sample in Wave 1. In this sample, $3.0 \%$ were Aboriginal and/or Torres Strait Islander, and for most respondents (66.7\%), both parents were born in Australia. Eight percent of the sample reported suicidal ideation within the past 12 months (as measured at Wave 2). The extent to which the sample conformed to masculine norms varied across the different subscales. There was greatest conformity to 'pursuit of status', 'heterosexual presentation', and 'emotional control'.

Results of the unadjusted and adjusted logistic regression models of the relationship between conformity to masculine norms and suicidal ideation are reported in Table 2. In adjusted models, conformity to violence norms $(O R=1.23,95 \% \mathrm{CI}: 1.03,1.47 ; p=0.026)$, and self-reliance norms $(O R=1.40,95 \% \mathrm{CI} 1.15,1.70$, $p=0.001$ ), were both associated with increased odds of reporting suicidal ideation. Greater conformity to heterosexual norms was associated with reduced odds of reporting suicidal ideation $(O R=0.80,95 \% \mathrm{CI}: 0.68$, $0.91, p=0.001)$. There were no associations with suicidal ideation for any of the other masculinity subscales.

While most of the sample identified as heterosexual ( $n=747), n=63$ identified as gay, bisexual, not sure or other. We therefore considered the possibility that associations may vary by sexual orientation (see Additional file 1: Table S2 for sample proportions), and ran models in which we further adjusted for sexual orientation. These produced estimates consistent with the main analyses (see Additional file 1: Table S3). We also restricted analysis to those adolescents identifying as heterosexual and found results consistent with the main analyses (see Additional file 1: Table S4).
Table 1 Sample descriptives $(n=829)$

\begin{tabular}{|c|c|c|}
\hline & $N$ & $\%$ \\
\hline \multicolumn{3}{|l|}{ Indigenous Australian Identity } \\
\hline Aboriginal and/or Torres Strait Islander & 25 & 3.0 \\
\hline Non-Indigenous & 804 & 97.0 \\
\hline \multicolumn{3}{|l|}{ Parents' Country of Birth } \\
\hline Both born in Australia & 554 & 66.8 \\
\hline One or both born elsewhere & 275 & 33.2 \\
\hline \multicolumn{3}{|l|}{ Area disadvantage } \\
\hline Quintile 1 (Most disadvantaged) & 142 & 17.1 \\
\hline Quintile 2 & 130 & 15.7 \\
\hline Quintile 3 & 184 & 22.2 \\
\hline Quintile 4 & 171 & 20.6 \\
\hline \multirow[t]{2}{*}{ Quintile 5 (Least disadvantaged) } & 202 & 24.4 \\
\hline & Mean & Standard Deviation \\
\hline \multicolumn{3}{|l|}{ Conformity to Masculine Norms } \\
\hline Pursuit of Status & 3.50 & 1.12 \\
\hline Dominance & 2.43 & 1.17 \\
\hline Emotional Control & 3.28 & 1.43 \\
\hline Heterosexual Presentation & 3.41 & 1.74 \\
\hline Playboy & 1.65 & 1.43 \\
\hline Power over Women & 1.10 & 1.05 \\
\hline Primacy of Work & 2.99 & 1.29 \\
\hline Risk Taking & 3.02 & 1.32 \\
\hline Self-Reliance & 2.46 & 1.23 \\
\hline Violence & 2.86 & 1.45 \\
\hline Winning & 2.46 & 1.26 \\
\hline \multirow[t]{2}{*}{ Total Score } & 29.13 & 5.87 \\
\hline & N & $\%$ \\
\hline \multicolumn{3}{|l|}{12 Month Suicidal Ideation, Wave 2} \\
\hline Yes & 69 & 8.3 \\
\hline No & 760 & 91.7 \\
\hline
\end{tabular}

\section{Discussion}

This study contributes new understandings of the associations between masculinity and suicidal ideation among adolescent males. Specifically, we found evidence that some dimensions of masculinity were associated with suicidal ideation: notably high conformity to violence and self-reliance among adolescents at 15-18 years was associated with higher odds of reporting suicidal ideation at 17-20 years, and higher conformity to norms related to heterosexuality was associated with lower odds of reporting suicidal ideation. To our knowledge, this is one of the first studies to quantitatively examine the associations between masculinity and suicidal ideation among young males. 
Table 2 The relationship between conformity to masculine norms (Wave 1) and thoughts of suicide (Wave 2), unadjusted and adjusted logistic regression models $(n=829)$

\begin{tabular}{|c|c|c|c|c|c|c|}
\hline & \multicolumn{3}{|c|}{ Unadjusted results } & \multicolumn{3}{|c|}{ Adjusted results $^{a}$} \\
\hline & $O R$ & $95 \% \mathrm{Cl}$ & $p$ value & $O R$ & $95 \% \mathrm{Cl}$ & $p$ value \\
\hline Pursuit of Status & 1.00 & $0.80,1.24$ & 0.974 & 1.01 & $0.81,1.27$ & 0.905 \\
\hline Dominance & 1.01 & $0.81,1.24$ & 0.961 & 1.00 & $0.81,1.23$ & 0.964 \\
\hline Emotional Control & 0.99 & $0.83,1.17$ & 0.885 & 0.98 & $0.82,1.17$ & 0.832 \\
\hline Heterosexual Presentation & 0.80 & $0.70,0.93$ & 0.003 & 0.80 & $0.68,0.91$ & 0.001 \\
\hline Playboy & 1.07 & $0.90,1.26$ & 0.460 & 1.07 & $0.91,1.27$ & 0.422 \\
\hline Power over Women & 0.96 & $0.75,1.21$ & 0.706 & 0.94 & $0.74,1.19$ & 0.602 \\
\hline Primacy of Work & 0.93 & $0.76,1.12$ & 0.435 & 0.91 & $0.75,1.11$ & 0.345 \\
\hline Risk Taking & 0.99 & $0.82,1.20$ & 0.924 & 0.99 & $0.82,1.19$ & 0.871 \\
\hline Self-Reliance & 1.42 & $1.17,1.72$ & $<0.001$ & 1.40 & $1.15,1.70$ & 0.001 \\
\hline Violence & 1.23 & $1.03,1.47$ & 0.025 & 1.23 & $1.03,1.47$ & 0.026 \\
\hline Winning & 0.88 & $0.72,1.08$ & 0.208 & 0.88 & $0.72,1.07$ & 0.194 \\
\hline CMNI Total & 1.00 & $0.96,1.04$ & 0.978 & 1.00 & $0.96,1.04$ & 0.868 \\
\hline
\end{tabular}

adjusted for Indigenous Australian identity, parent country of birth, and area disadvantage

The results for violence indicate that each unit increase in conformity to violence was associated with $23 \%$ higher odds of reporting suicidal ideation. This is consistent with evidence showing that violent behavior is a risk factor for suicide in adults [17]. While as a whole, the sample did not overwhelmingly endorse violence as a mechanism to solve problems, those who did were more likely to think about suicide, illustrating the risky nature of this dimension of masculinity. There is some evidence that males may be at greater risk of death by suicide because they are socialized to conform to certain masculine norms that foster engagement with painful and provocative life events, resulting in greater 'acquired capability' for suicide [26]. It is also known that, compared to females, males are more likely to die by suicide using violent means [61]. Importantly, while hegemonic masculinity values physical strength and toughness, it does not equate with physical violence: violence, however, is sometimes used to demonstrate this physical strength and toughness [8].

The associations observed in this analysis for selfreliance show that each unit increase in self-reliance is associated with $40 \%$ increased odds of reporting suicidal ideation. These results are concordant with other work among adults, where self-reliance has been associated with suicidal ideation [49] and mental health problems [43]. The self-reliance items used in this scale tap into affective and behavioral responses to help-seeking. Critically then, these results reveal that some of the young men in this sample reporting suicidal ideation have also reported high conformity to norms that indicate resistance to help-seeking. On face-value, self-reliance can be a positive attribute if it fosters independence, however, the potentially positive effects of self-reliance may be circumscribed if it also inhibits communication and help-seeking in times of distress or crisis. Mental health stigma is known to be a barrier to help-seeking, however recent work highlighted that for young men, this is perhaps more keenly experienced because poor mental health, and help-seeking are both at odds with their internalized masculine norms [39].

Our findings that heterosexual presentation was associated with reduced suicidal ideation (20\% lower odds for each unit increase in conformity to heterosexual presentation) was unexpected. The results may evince the protective effect of conforming to socially condoned norms. Hegemonic masculinity is clearly heteronormative. Alignment with dominant masculine norms, and more pointedly, the knowledge that one does not deviate from this heterosexual norm, is likely to confer some level of protection for young males' mental health. The obverse of the relationship that we observed between high endorsement of heterosexual norms and low suicidal ideation is that low endorsement of heterosexual norms is associated with increased odds of reporting suicidal ideation. Such results do not indicate that being heterosexual is protective, but rather, highlight: firstly, the broader buffering effect of conforming to heterosexual masculine norms; and secondly, the potential to avoid the penalties that arise if deviating from socially accepted norms.

Given that there is a well-established literature documenting the fact that sexual minority young men and adolescents are at elevated risk of suicide and self-harm $[20,51,55]$, we conducted sensitivity analysis in which we firstly controlled for sexual orientation, and then restricted our sample to heterosexual-identifying 
adolescents. The results persisted in both sets of sensitivity analysis. It is widely accepted that heterosexuality is a core component of constructions of hegemonic masculinity [14,32] and that "to a greater or lesser extent hegemonic masculinity is constructed as a gender position that is as much 'not gay' as it is 'not female" ([32], p. S113). Certainly, the importance of heterosexuality among adolescents in this sample was evidenced by the high mean score for that subscale, although we note that the large standard deviation suggests that this was not uniformly endorsed. Compared to $18-55$ year-olds in the same dataset [49], the adolescents in this sample expressed greater conformity to heterosexual norms. The practice of constructing and affirming masculinity through the assertion of heterosexuality among young males has been observed elsewhere [23]. Froyum's research revealed the ways that adolescent males (and females) disassociate themselves from homosexuality and other non-heterosexual sexual identities to construct and affirm their heterosexuality [23].

Given that they are situated outside the heteronormative bounds of hegemonic masculinity, it is not surprising that those young males in our sample not conforming to the hegemonic norm of heterosexual presentation fare less well. This is problematic, not only for the negative impact on young people who are not heterosexual, but also because homophobia, and or the fear of being thought to be gay, can act as a barrier to intimacy among men [14]; something that may impart other negative impacts on them in the future, even if not observed now.

These findings suggesting that certain elements of masculinity may place young men at risk of suicidal ideation have implications for suicide prevention programs among adolescent boys. At a broad level, these results indicate the pervasive power of social norms in defining consensual expectations about what group members do, and should do [11]. Previously, gender norms have been examined in relation to the way they delimit the roles, autonomy and control that women have over their lives. Yet, it is increasingly recognized that gender norms and attitudes may also underpin adverse health behaviors and outcomes in boys and men $[34,35]$. Recognizing the challenging and often conflicting messages that young adolescents face regarding masculinity is vital [40]. There is clearly a need to destigmatize mental health, and also foster new understandings of masculinity that incorporate help-seeking into masculine ideals [39].

Jewkes et al. [31] proposed an ecological approach to the transformation of masculinities in adolescents. Such an approach seeks to understand and address the drivers of social norms at all levels- societal, institutional (such as schools), interpersonal and individual - and should seek to understand how different factors or identities might intersect [31]. Jewkes et al. [31] proposed that interventions must move away from one dimensional, homogeneous depictions of masculinity. Drawing on Connell's work [14, 16], they proposed that interventions should emphasize the heterogeneity of masculinity, avoid stereotypes, focus on similarities between men and women, engage with, and acknowledge fears and vulnerabilities and address homophobia [31]. It is possible that relaxing rigid norms regarding masculinity and encouraging acceptance of more diverse masculinities will deliver benefits beyond suicide and mental health improvements for adolescent boys, and contribute to better health and wellbeing in the wider population [22, 36].

Further work is needed to examine the associations observed in this analysis over time (as more waves of data become available), and across different age groups, to understand whether these associations reflect cohort effects, or developmental stages. It is also crucial to understand how these changes relate to other personal, occupational and well-being indicators, regardless of the drivers. Furthermore, it is possible that specific dimensions of masculinity are both protective and also risk factors at different developmental stages: the dynamic nature of these associations needs to be understood.

Dismantling masculine norms to facilitate help-seeking is vital, however it is also important that once adolescent males do seek help, mental health services are available and appropriate to meet their needs - ideally personcentered approaches that acknowledge the diversity of men, and the diversity of their needs [56].

There are several strengths of this analysis. We used a large sample of Australian male adolescents, which strengthens the basis for statistical inference. We also note the use of a validated measure of masculinity. The original 94-item CMNI had good construct validity, and discriminant validity, and the 22-item instrument has been shown to correlate well with the original scale [60]. Additionally, the CMNI-22 has been widely used and is positively regarded. While in this study, basic psychometric parameters of the CMNI were analyzed (i.e. factor structure, item loadings and internal consistency), it should be acknowledged that an exhaustive evaluation of its psychometric properties has not been conducted on an Australian adolescent sample. We also raise the possibility that the construct validity of some of the subscales was low: in particular, it is possible that the items for heterosexual presentation do not align with the construct they are purported to measure in this population (potentially underpinning the findings for heterosexual presentation).

We note that significant measurement differences across ethnic groups have been observed, with evidence that the 
scale is more theoretically consistent for White American men compared to Asian Americans [30]. Other evidence also indicates that masculinity may be understood, experienced and expressed differently across different ethnic groups and cultural contexts [27], thus the results may not be generalizable to Indigenous Australians and Australians of ethnic minority backgrounds. Further work using qualitative methods is needed to examine how conformity to masculinity may vary across ethnicity and Indigenous identity in Australian adolescents.

As both masculinity and suicidal ideation were selfreported, dependent measurement error, which can arise when two or more variables are based on self-reported subjective responses from the same respondent [63], may have biased findings.

While there is a precedent for the use of single-item suicidal ideation measures $[44,48]$, there is some evidence that single-item measures may result in a higher proportion of false positives and false negatives [42]. If this occurred in this study, there is potential that it led to some degree of misclassification bias and potentially spurious findings. A further limitation of single-item measures such as this one is that they inadequately capture differences in the severity or frequency of ideation or attempts [42]. It is impossible to ascertain, for example, whether a person was actively planning to engage in suicidal behavior, whether a suicide behavior was stopped, or whether these were simply fleeting and non-serious thoughts.

Selection bias due to missing data potentially affected these results, although we note that for most variables, there was $<4 \%$ missing from the eligible sample, and this is unlikely to have biased results. Because our sample comprised of adolescent males (with no parent-reported information on household income or occupation), common socio-economic confounders were either unavailable/not obtained (household income, parental occupation), or not yet realized (educational attainment). We were therefore unable to include these possible confounders of the relationship between masculinity and suicidal ideation in analytical models. This may have introduced some bias, as there is evidence that constructions of masculinity differ across socio-economic position (SEP) [14], and that more disadvantaged groups are at greater risk of suicide [28]. However, we note that while we were unable to control for individual SEP, we did control for area SEP. Given evidence that for adolescent males, enactments of masculinity [12] and suicidal behaviors [5] are known to vary by neighborhood/area deprivation, we contend that by controlling for area SEP we have captured much of the confounding that may have been induced by individual SEP.

\section{Conclusions}

In conclusion, this study presents quantitative evidence of associations between elements of masculinity and suicidal ideation in a sample of adolescents. Among the adolescent males in this sample, we found that high conformity to norms of violence and self-reliance was associated with greater odds of reporting suicidal ideation, while high conformity to norms of heterosexual presentation was associated with reduced odds of reporting suicidal ideation. Maximizing adolescent health is key to optimizing adult health and well-being, and these results highlight the potential importance of presenting multiple ways of being a male among adolescents. Facilitating a relaxation of norms regarding self-reliance to encourage help-seeking is vital, and dismantling heteronormative masculine norms is likely to benefit the broad population of males, not only those who do not conform to heterosexual and other masculine norms.

\section{Supplementary information}

Supplementary information accompanies this paper at https://doi.org/10. 1186/s12888-020-2475-y.

Additional file 1: Table S1. Summary of missing data. Table S2. Sexual orientation statistics. Table S3. The relationship between conformity to masculine norms and thoughts of suicide controlling for sexual orientation, $(n=810)$. Table S4. The relationship between conformity to masculine norms and thoughts of suicide, restricted to heterosexual young men, $(n=747)$.

Additional file 2: Table S5. Factor loadings based on confirmatory factor analysis of the CMNI among Ten to Men sample of Australian males aged 15-18 years. Table S6. Concordance between CMNI scales and factor loadings.

\section{Abbreviations \\ Cl: Confidence interval; CMNI: Conformity to Masculine Norms Inventory; IRSD: Index of Relative Socio-Economic Disadvantage; OR: Odds ratio; SA: Statistical Area; SEP: Socio-economic position}

\section{Acknowledgements}

This paper uses data from Ten to Men, The Australian Longitudinal Study on Male Health. Ten to Men is funded by the Australian Government Department of Health, and is conducted by the Australian Institute of Family Studies (AIFS). The findings and views reported in this paper are those of the authors and should not be attributed to AIFS or the Australian Government Department of Health. We thank the Australian boys whose data are analyzed here, as well as the broader sample of Australian males who participated in the study.

\section{Authors' contributions}

TLK conceived the study, interpreted the results and wrote the manuscript: MS conducted the analysis, and contributed to drafts of the manuscript; VS contributed to interpretation of results and drafts of the manuscript; GD contributed to interpretation of results and drafts of the manuscript; DC contributed to interpretation of results and drafts of the manuscript; $A O$ contributed to interpretation of results and drafts of the manuscript; KK contributed to interpretation of results and drafts of the manuscript; AM contributed to interpretation of results and drafts of the manuscript. All authors read and approved the final manuscript.

\section{Funding}

This work was supported by a University of Melbourne, Melbourne School of Population and Global Health, Business Improvement Program (BIP) Reinvestment grant and an Australian Research Council Linkage Project Gender equality in Australia: impact on social, economic and health outcomes (LP 180100035), and an NHMRC Partnership Project grant (APP1134499). AM is supported by a Victorian Health and Medical Research 
Fellowship, TK is supported by a University of Melbourne Early Career Researcher Grant (1858815), and VS is supported by a University of Melbourne Early Career Researcher Grant (603783).

The funding bodies had no role in the design of the study, data collection, analysis, interpretation of results or the writing of this manuscript.

\section{Availability of data and materials}

The datasets generated and/or analyzed during the current study are not publicly available due to ethics agreements which preclude this. Ten to Men data are available at the Australian Data Archive (https://dx.doi.org/10.26193/ V2IVIG.)

\section{Ethics approval and consent to participate}

Ten to Men received approval from the University of Melbourne Human Research Ethics Committee and conformed to the principles embodied in the Declaration of Helsinki. All participants aged 15-18 provided written consent to participate, and parents of 15-17 years old participants also provided written consent for their boys' participation.

\section{Consent for publication}

Not applicable.

\section{Competing interests}

The authors declare that they have no competing interests.

\section{Author details}

${ }^{1}$ Centre for Health Equity, Melbourne School of Population and Global Health, The University of Melbourne, Bouverie St, Carlton 3010, Australia. ${ }^{2}$ Centre for Workplace Leadership, Department of Management and Marketing, The University of Melbourne, Melbourne, Victoria 3010, Australia. ${ }^{3}$ Longitudinal and Lifecourse Studies, Australian Institute of Family Studies, Honorary Melbourne University Fellow, Southbank, VIC 3006, Australia. ${ }^{4}$ Centre for Mental Health, Melbourne School of Population and Global Health, The University of Melbourne, Bouverie St, Carlton 3010, Australia. ${ }^{5}$ Food and Mood Centre, IMPACT Strategic Research Centre, Deakin University, Geelong 3220, Australia. ${ }^{6}$ Turner Institute for Brain and Mental Health, School of Psychological Sciences, Monash University, Clayton 3800, Australia.

Received: 10 April 2019 Accepted: 31 January 2020

Published online: 12 May 2020

\section{References}

1. Australian Bureau of Statistics (ABS). Causes of Death, Australia, 2018: Catalogue No. 3303.0. Canberra: ABS; 2018.

2. American Psychological Association, Boys and Men Guidelines Group. APA guidelines for psychological practice with boys and men. Washington: American Psychological Association. 2018. Retrieved from http://www.apa. org/about/policy/psychological-practice-boys-men-guidelines.pdf.

3. Amin A, Kågesten A, Adebayo E, Chandra-Mouli V. Addressing gender socialization and masculinity norms among adolescent boys: policy and programmatic implications. J Adolesc Health. 2018;62:S3-5.

4. Australian Bureau of Statistics (ABS). Socio-Economic Indexes for Areas (SEIFA) 2016: Technical Paper \#2033.0.55.001. Canberra: ABS; 2018.

5. Ayton A, Rasool H, Cottrell D. Deliberate self-harm in children and adolescents: association with social deprivation. Eur Child Adolesc Psychiatry. 2003;12:303-7.

6. Bandara D, Howell L, Daraganova G. Ten to Men: The Australian Longitudinal Study on Male Health, Release 2.1 (Waves 1-2). 2019; https:// doi.org/10.26193/N2IVIG,ADADataverse,V2.

7. Blakemore JEO. Children's beliefs about violating gender norms: boys Shouldn't look like girls, and girls Shouldn't act like boys. Sex Roles. 2003;48: 411-9. https://doi.org/10.1023/A:1023574427720.

8. Bourgois $P$. In search of masculinity: violence, respect and sexuality among Puerto Rican crack dealers in East Harlem. Br J Criminol. 1996;36:412-27. https://doi.org/10.1093/oxfordjournals.bjc.a014103.

9. Canetto SS, Sakinofsky I. The gender paradox in suicide. Suicide Life Threat Behav. 1998;28:1-23.

10. Centers for Disease Control and Prevention. Youth risk behaviour survey questionnaire. 2011. Available at www.cdc.gov/yrbs.
11. Cialdini R, Trost M. Social influence: social norms, conformity and compliance. In: Handb. Soc. Psychol, vol. 2; 1998. https://doi.org/10.2307/ 2654253.

12. Cleary A. Suicidal action, emotional expression, and the performance of masculinities. Soc Sci Med. 2012;74:498-505. https://doi.org/10.1016/j. socscimed.2011.08.002.

13. Coleman D. Traditional masculinity as a risk factor for suicidal ideation: cross-sectional and prospective evidence from a study of Young adults. Arch Suicide Res. 2015;19:366-84. https://doi.org/10.1080/13811118.2014. 957453.

14. Connell R. Masculinities. Second. ed. Cambridge: A\&U Academic; 2005a.

15. Connell R. Growing up masculine: rethinking the significance of adolescence in the making of masculinities. Irish J Sociol. 2005b;14:11-28. https://doi.org/10.1177/079160350501400202.

16. Connell R. Gender and Power. Sydney: Allen \& Unwin; 1987.

17. Conner KR, Cox C, Duberstein PR, Tian L, Nisbet PA, Conwell Y. Violence, alcohol, and completed suicide: a case-control study. Am J Psychiatry. 2001; 158:1701-5. https://doi.org/10.1176/appi.ajp.158.10.1701.

18. Courtenay WH. Constructions of masculinity and their influence on men's well-being: a theory of gender and health. Soc Sci Med. 2000;50:1385-401. https://doi.org/10.1016/S0277-9536(99)00390-1.

19. Currier D, Pirkis J, Carlin J, Degenhardt L, Dharmage SC, Giles-Corti B, Gordon I, Gurrin L, Hocking J, Kavanagh A, Keogh LA, Koelmeyer R, LaMontagne AD, Schlichthorst M, Patton G, Sanci L, Spittal MJ, Studdert DM, Williams J, English DR. The Australian longitudinal study on male healthmethods. BMC Public Health. 2016;16:1030. https://doi.org/10.1186/s12889016-3698-1.

20. Daraganova G. Self-harm and suicidal behaviour of young people aged 1415 years old. In: The Australian Institute of Family Studies (AIFS). Longitudinal Study of Australian Children Annual Statistical Report 2016. p. 119-44. Melbourne: AIFS; 2017.

21. De Leo D, Sveticic J, Milner A. Suicide in Indigenous people in Queensland, Australia: trends and methods, 1994-2007. Aust N Z J Psychiatry. 2011;45: 532-8. https://doi.org/10.3109/00048674.2011.570310.

22. Fine C, Sojo V, Lawford-Smith $\mathrm{H}$. Why does workplace gender diversity matter? Justice, organizational benefits, and policy. Soc Issues Policy Rev. 2019:12064. https://doi.org/10.1111/sipr.12064.

23. Froyum CM. "At least I'm not gay": heterosexual identity making among poor black teens. Sexualities. 2007;10:603-22. https://doi.org/10.1177/ 1363460707083171.

24. Gerdes Z, Levant R. Complex relationships among masculine norms and health/ well-being outcomes: correlation patterns of the conformity to masculine norms inventory subscales. Ment Health Wellbeing. 2018;12:22940. https://doi.org/10.1177/1557988317745910.

25. Gore FM, Bloem PJN, Patton GC, Ferguson J, Joseph V, Coffey C, Sawyer SM, Mathers CD. Global burden of disease in young people aged 10-24 years: a systematic analysis. Lancet. 2011;377:2093-102. https://doi.org/10.1016/ S0140-6736(11)60512-6.

26. Granato S, Smith P, Selwyn C. Acquired capability and masculine gender norm adherence: potential pathways to higher rates of male suicide. Psychol Men Masculinity. 2015;16:246-53.

27. Griffith DM, Gunter K, Watkins DC. Measuring masculinity in research on men of color: findings and future directions. Am J Public Health. 2012;102. https://doi.org/10.2105/AJPH.2012.300715.

28. Gunnell D, Wheeler B, Chang SS, Thomas B, Sterne JAC, Dorling D. Changes in the geography of suicide in young men: England and Wales 1981-2005. J Epidemiol Community Health. 2012;66:536-43. https://doi.org/10.1136/jech. 2009.104000.

29. Hawton K, Saunders KEA, O'Connor RC. Self-harm and suicide in adolescents. Lancet. 2012;379:2373-82. https://doi.org/10.1016/S0140-6736(12)60322-5.

30. Hsu K, Iwamoto DK. Testing for measurement invariance in the conformity to masculine norms-46 across white and Asian American college men: development and validity of the CMNI-29. Psychol. Men Masculinity. 2014; 15:397-406. https://doi.org/10.1037/a0034548.

31. Jewkes R, Flood M, Lang J. From work with men and boys to changes of social norms and reductions of inequities in gender relations: a conceptual shift in prevention of violence against women and girls. Lancet. 2015a;385:1580-9.

32. Jewkes R, Morrell R, Hearn J, Lundqvist E, Blackbeard D, Lindegger G, Quayle M, Sikweyiya Y, Gottzén L. Hegemonic masculinity: combining theory and practice in gender interventions. Cult Health Sex. 2015b;17:96-111. https:// doi.org/10.1080/13691058.2015.1085094. 
33. Joiner TE. Why people die by suicide. Cambridge and London: Harvard University Press; 2005.

34. Kågesten A, Gibbs S, Blum RW, Moreau C, Chandra-Mouli V, Herbert A, Amin A. Understanding factors that shape gender attitudes in early adolescence globally: a mixed-methods systematic review. PLoS One. 2016;11:e0157805. https://doi.org/10.1371/journal.pone.0157805.

35. King TL, Singh A, Milner A. Associations between gender-role attitudes and mental health outcomes in a nationally representative sample of Australian adolescents. J Adolesc Health. 2019;65:72-8. https://doi.org/10.1016/j. jadohealth.2019.01.011.

36. Kiselica MS, Benton-Wright S, Englar-Carlson M. Accentuating positive masculinity: A new foundation for the psychology of boys, men, and masculinity. In Y. J. Wong \& S. R. Wester (Eds.), APA handbooks in psychology ${ }^{\circledast}$. APA handbook of men and masculinities. 2015; p. 123-143. American Psychological Association. https://doi.org/10.1037/14594-006.

37. Klonsky ED, May AM, Saffer BY. Suicide, suicide attempts, and suicidal ideation. Annu Rev Clin Psychol. 2016;12:14.1-14.24. https://doi.org/10.1146/ annurev-clinpsy-021815-093204.

38. Langhinrichsen-Rohling J, Friend J, Powell A. Adolescent suicide, gender, and culture: a rate and risk factor analysis. Aggress Violent Behav. 2009;14: 402-14. https://doi.org/10.1016/j.avb.2009.06.010.

39. Lynch L, Long M, Moorhead A. Young men, help-seeking, and mental health services: exploring barriers and solutions. Am J Mens Health. 2018;12: 138-49. https://doi.org/10.1177/1557988315619469.

40. Mac An Ghaill M, Haywood C. Understanding boys': thinking through boys, masculinity and suicide. Soc Sci Med. 2012;74:482-9. https://doi.org/10. 1016/j.socscimed.2010.07.036.

41. Mahalik JR, Locke BD, Ludlow LH, Diemer MA, Scott RPJ, Gottfried M, Freitas G. Development of the conformity to masculine norms inventory. Psychol Men Masculinity. 2003:4:3-25. https://doi.org/10.1037/1524-9220.4.1.3.

42. Millner AJ, Lee MD, Nock MK. Single-item measurement of suicidal behaviors: validity and consequences of misclassification. PLoS One. 2015;10: e0141606. https://doi.org/10.1371/journal.pone.0141606.

43. Milner A, Kavanagh A, King T, Currier D. The influence of masculine norms and occupational factors on mental health: evidence from the baseline of the Australian longitudinal study on male health. Am J Mens Health. 2018; 12:696-705. https://doi.org/10.1177/1557988317752607.

44. Milner AJ, Shields M, Currier D, King TL. Male-dominated occupations, employment status, and suicidal behaviors among Australian men: a followup study using two waves of data from the Ten to Men cohort. Crisis. 2020; 41:54-63. https://doi.org/10.1027/0227-5910/a000610.

45. Nock MK. Self-Injury. Annu Rev Clin Psychol. 2010;6:339-63. https://doi.org/ 10.1146/annurev.clinpsy.121208.131258.

46. Owen J. Assessing the Factor Structures of the 55-and 22-Item Versions of the Conformity to Masculine Norms Inventory. Am. J. Mens. Health. 2011;5:118-128.

47. Patel V, Flisher AJ, Hetrick S, McGorry P. Mental health of young people: a global public-health challenge. Lancet. 2007;369:1302-13. https://doi.org/10. 1016/S0140-6736(07)60368-7.

48. Pirkis J, Currier D, Butterworth P, Milner A, Kavanagh A, Tibble H, Robinson J, Spittal MJ. Socio-economic position and suicidal ideation in men. Int J Environ Res Public Health. 2017a;14. https://doi.org/10.3390/ijerph14040365.

49. Pirkis J, Spittal MJ, Keogh L, Mousaferiadis T, Currier D. Masculinity and suicidal thinking. Soc Psychiatry Psychiatr Epidemiol. 2017b;52:319-27. https://doi.org/10.1007/s00127-016-1324-2.

50. Rasmussen ML, Haavind H, Dieserud G. Young men, masculinities, and suicide. Arch Suicide Res. 2018;22:327-43. https://doi.org/10.1080/13811118. 2017.1340855.

51. Remafedi G. Sexual orientation and youth suicide. J Am Med Assoc. 1999. https://doi.org/10.1001/jama.282.13.1291-JMS1006-6-1.

52. Ribeiro JD, Franklin JC, Fox KR, Bentley KH, Kleiman EM, Chang BP, Nock MK. Self-injurious thoughts and behaviors as risk factors for future suicide ideation, attempts, and death: a meta-analysis of longitudinal studies. Psychol Med. 2016;46:225-36.

53. Rice S, Fallon B, Bambling M. Men and depression: the impact of masculine role norms throughout the lifespan. Aust Educ Dev Psychol. 2011;28:133-44. https://doi.org/10.1375/aedp.28.2.133.

54. Rice SM, Purcell R, McGorry PD. Adolescent and Young adult male mental health: transforming system failures into proactive models of engagement. J Adolesc Health. 2018;62:S9-S17. https://doi.org/10.1016/JJADOHEALTH.2017.07.024.

55. Russell ST. Sexual minority youth and suicide risk. Am Behav Sci. 2003;46: 1241-57. https://doi.org/10.1177/0002764202250667.
56. Seidler ZE, Rice SM, River J, Oliffe JL, Dhillon HM. Men's mental health services: the case for a masculinities model. J Mens Stud. 2018;26:92-104. https://doi.org/10.1177/1060826517729406.

57. Sirin SR, Mccreary DR, Mahalik JR. Differential reactions to men and women's gender role transgressions: perceptions of social status, sexual orientation, and value dissimilarity; 2004.

58. Sveticic J, De Leo D. The hypothesis of a continuum in suicidality: a discussion on its validity and practical implications. Ment IIIn. 2012;4:e15. https://doi.org/10.4081/mi.2012.e15.

59. The Men's Project, Flood M. The man box: a study on being a young man in Australia authors. Melbourne: Jesuit Social Services; 2018.

60. Thompson EH, Bennett KM. Measurement of masculinity ideologies: a (critical) review. Psychol Men Masculinity. 2015;16:115-33. https://doi.org/10. 1037/a0038609.

61. Tsirigotis K, Gruszczynski W, Tsirigotis M. Gender differentiation in methods of suicide attempts. Med Sci Monit. 2011;17:PH65-70. https://doi.org/10. 12659/MSM.881887.

62. Turecki G, Brent DA. Suicide and suicidal behaviour. Lancet. 2016;387:122739. https://doi.org/10.1016/S0140-6736(15)00234-2.

63. VanderWeele TJ, Hernán MA. Results on differential and dependent measurement error of the exposure and the outcome using signed directed acyclic graphs. Am J Epidemiol. 2012;175:1303-10. https://doi.org/10.1093/ aje/kwr458.

64. Wong YJ, Ho M-HR, Wang S-Y, Keino Miller IS. Meta-analyses of the relationship between conformity to masculine norms and mental healthrelated outcomes. J Couns Psychol. 2017;64:80-93. https://doi.org/10.1037/ cou0000176.supp.

65. World Health Organization. Health for the world's adolescents: a second chance in the second decade. Geneva. 2014. https://doi.org/10.1016/j. jadohealth.2014.10.260.

66. Young R, Johnson D. Methods for handling missing secondary respondent data. J Marriage Fam. 2013;75:221-34. https://doi.org/10.1111/j.1741-3737. 2012.01021.x.

\section{Publisher's Note}

Springer Nature remains neutral with regard to jurisdictional claims in published maps and institutional affiliations.

Ready to submit your research? Choose BMC and benefit from:

- fast, convenient online submission

- thorough peer review by experienced researchers in your field

- rapid publication on acceptance

- support for research data, including large and complex data types

- gold Open Access which fosters wider collaboration and increased citations

- maximum visibility for your research: over $100 \mathrm{M}$ website views per year

At BMC, research is always in progress.

Learn more biomedcentral.com/submissions 